was to re-orientate to palliative care which the parents accepted.

Conclusion These increasingly challenging ethical cases result in significant moral distress among neonatal staff that already operate in an high stress environment. In some cases it results in the prolongation of suffering of these babies. This impacts on the moral well being of the nursing and medical staff looking after these babies over this challenging period. We need to remain focused as advocates for these vulnerable babies and continue to keep their best interest at the heart of care we provide. Staff support is also paramount in ensuring that their moral distress is addressed and supported.

\section{G479(P) CAN PARENTS-TO-BE THAT FAIL TO ENGAGE WITH ANTENATAL SCREENING SERVICES HARM US ALL?}

${ }^{1,2} \mathrm{C}$ Kanaris. 'North West and North Wales Paediatric Transport Service, Manchester
University NHS Foundation Trust, Manchester, UK; ${ }^{2}$ The Centre for Social Ethics and Policy,
School of Law, The University of Manchester, Manchester, UK

10.1136/archdischild-2018-rcpch.467

I make a case in favour of a parental duty to engage with antenatal screening services and in utero therapies. I explore the question of whether ignorance of one's future child's genetic makeup in the antenatal setting causes harm, and if so whether we have a moral obligation to avoid it by employing antenatal screening and in utero therapies available to us. I review current philosophical theories on harm, as well as current clinical advances that can improve the health children that will come to exist I focus particularly on refuting arguments favouring one's alleged 'right to genetic ignorance' and argue that both Mill's Harm principle and Kant's definition of autonomy can be applied in the antenatal setting in order to protect future children. I analyse whether, where safe and effective in utero treatments are available and not up-taken, resulting in children being brought to existence in a more impaired state than they otherwise would have, amounts to harm. I also consider whether harm can be caused to parents themselves, siblings and wider society by a failure to engage with antenatal screening and in utero therapies.

\section{G480(P) THE EXPERIENCES, ATTITUDES AND PRACTICES OF NURSES WORKING IN A PAEDIATRIC INTENSIVE CARE UNIT CARING FOR BABIES AND CHILDREN AT THE END OF LIFE: A QUALITATIVE STUDY}

'P du Pré, ${ }^{1 J}$ Brierley, ${ }^{2} \mathrm{~J}$ Koffman. ${ }^{1}$ Paediatric and Neonatal Intensive Care Unit, Great Ormond Street Hospital, London, UK; ${ }^{2}$ Palliative Care, King's College London, London, UK

\subsection{6/archdischild-2018-rcpch.468}

Introduction Of the $74 \%$ of UK childhood deaths that occur in hospital, an increasing number - up to $65 \%$ - occur in PICU. There is little information about the impact of this on those who provide minute-to minute care of the children and their families, the bedside nurses.

Aims The objectives of this study were to explore the lived experiences, attitudes and practice of nurses delivering PICU end-of-life care (EOLC).

Method Maximum variation sampling: range of roles and clinical experience to identify potential participants who may hold different views.
Qualitative approach with face-to-face semi-structured interviews away from the bedside. (Build rapport, tackle hierarchy and enable undiluted, in depth, exploration.)

Researcher introduced broad topic areas, then specific questioning responsive to participant replies.

Areas: clinical background ('ice-breaker'); experiences caring for children at EOLC; view of what good outcome entails; any experiences taking children home or to hospice for EOLC.; challenges faced providing EOLC; discussions surrounding EOLC (who/when/how documentation. Recollected case EOLC done well and one where done badly

Interview process designed to maximise richest data. Face-toface interviews to obtain detailed investigation of participant's personal perspectives within complex systems. Qualitative methodology sought and preserved original lived experience of participants and offer insight into individuals' subjective livedexperiences, providing rich descriptions contextualised to participants personal settings and social meanings. Data recorded, transcribed and analysed thematically.

Results Seven participants. Main themes were facilitating factors and challenges faced providing optimal EOLC for children and families. Themes included: offering choice to families; meeting family's needs; past experience; relationships with families; conflict in a few hard cases; communication; uncertainty and lack of time. Participants consider they do this well most of the time and find this aspect of work hugely satisfying when done well but extremely hard when there are difficulties

Conclusions This study provided rich insights into the lived experiences of nurses caring for children at end of life in PICU. We demonstrated the values and models of good practice as well as the barriers encountered. There continues to be a need to advance the evidence base in order to improve this aspect of care.

\section{International Network of Paediatric Surveillance Units}

\section{GLOBAL SPREAD OF STEC AND MANAGING THE CONSEQUENCES}

${ }^{1}$ A Smith-Palmer, ${ }^{1} G$ Hawkins, ${ }^{1} S$ Couper, ${ }^{2} H$ Maxwell, ${ }^{2} B$ Reynolds, ${ }^{2} V$ Harkins, ${ }^{3} \mathrm{~L}$ Allison, ${ }^{3} \mathrm{M}$ Hanson. ${ }^{1}$ Health Protection Scotland, Glasgow, UK; ${ }^{2}$ Royal Hospital for Children, Glasgow, UK; ${ }^{3}$ Scottish E.coli 0157/STEC Reference Laboratory, Department of Laboratory Medicine, Royal Infirmary Edinburgh, Edinburgh, UK

\subsection{6/archdischild-2018-rcpch.469}

Shiga toxin-producing E. coli (STEC) was first recognised as a food-borne pathogen in 1982, when it was isolated during two outbreaks of haemorrhagic colitis associated with undercooked burgers in the United States. Since then, STEC has become established as an important global gastrointestinal pathogen.

STEC can colonise the gastrointestinal tract of wild, farmed, and domesticated animals and be shed in their faeces. Cattle are considered the most important reservoir for STEC in humans; infection in cattle is non-pathogenic.

Transmission to humans can occur as a result of direct contact with STEC-contaminated faecal material, from handling or petting animals or by exposure to faecally contaminated soil or vegetation during recreational or occupational activities. 